\title{
REMOTE SENSING OF ENVIRONMENTAL POLLUTION ON TEESSIDE
}

\author{
J. L. VAN Genderen \\ Department of Geography, University of Sheffield, Sheffield, Great Britain
}

ABSTRACT

A preliminary reconnaissance is being carried out to study the methods and procedures most useful for the detection of vegetation stress resulting from the various forms of environmental pollution, in the industrial area of Teesside, NE England, by means of a multiband remote sensing programme. Present results indicate the need for a carefully integrated programme of image analysis, as well as for field and laboratory methods. Sequential aerial multiband photography is an extremely useful technique for plotting the spread of industries and pollution with time, as well as for examining the changes in vegetation and land-use. Colour-infrared film is considered to be the single most useful remote sensing device for vegetation stress determination, as plants under stress are usually accompanied by a loss of infrared reflectance from the affected verdure. Image enhancement techniques are considered to be useful tools in delimiting certain areas under stress. The use of multiband photography, together with other remote sensing techniques, can greatly assist in the determination of areas of vegetation stress.

\section{INTRODUCTION}

During the past twenty years, the polluted environment has become one of the major concerns of industrial societies. Continued growth in the industrial development of the Teesside area and in the wastes from an ever-increasing number of sources, together with the need to preserve nature in its many forms, have focused attention on the burgeoning problems of environmental pollution and the demand for the early and reliable detection of vegetation stress (in this study, 'vegetation stress' refers to plants which have an abnormal bio-physical response due to the disruption of their normal physiological functions) caused by pollution, so that effective control measures can be introduced.

221

Environ. Pollut. (6) (1974)—C Applied Science Publishers Ltd, England, 1974

Printed in Great Britain 
The complexity of the problem has produced a large number of scientific investigations. Studies of the effects of atmospheric pollution upon vegetation have, in the last decade, been adequately treated and reviewed (e.g. Agricultural Research Council, 1967; Brandt, 1962; Heck, 1966; Thomas, 1961). However, most emphasis has been placed either upon economically-important plants such as agricultural crops and conifers, or on lichens, which, because of their high sensitivity to atmospheric pollution, are considered to be useful 'indicator plants' for levels of pollution. Up to the present time, very little work has been done in the United Kingdom on the detection of the effects of pollution on plants by means of remote sensing techniques, despite the promising results achieved by those workers who have experimented with remote sensing methods in other countries (Hildebrandt \& Kenneweg, 1968; Olson, 1971; Pollanschütz, 1968; Weber \& Polcyn, 1972; Wert, 1969; Wolff, 1967). This paper describes preliminary investigations into the determination of methods of detecting areas of vegetation under stress as a result of pollution, and into the development of an integrated programme or methodology for determining vegetation stress by means of a multiband remote sensing reconnaissance programme.

Teesside, the area under investigation, is situated in the north-east of England (Fig. 1). Multiband aerial photography was taken of the area from Redcar to

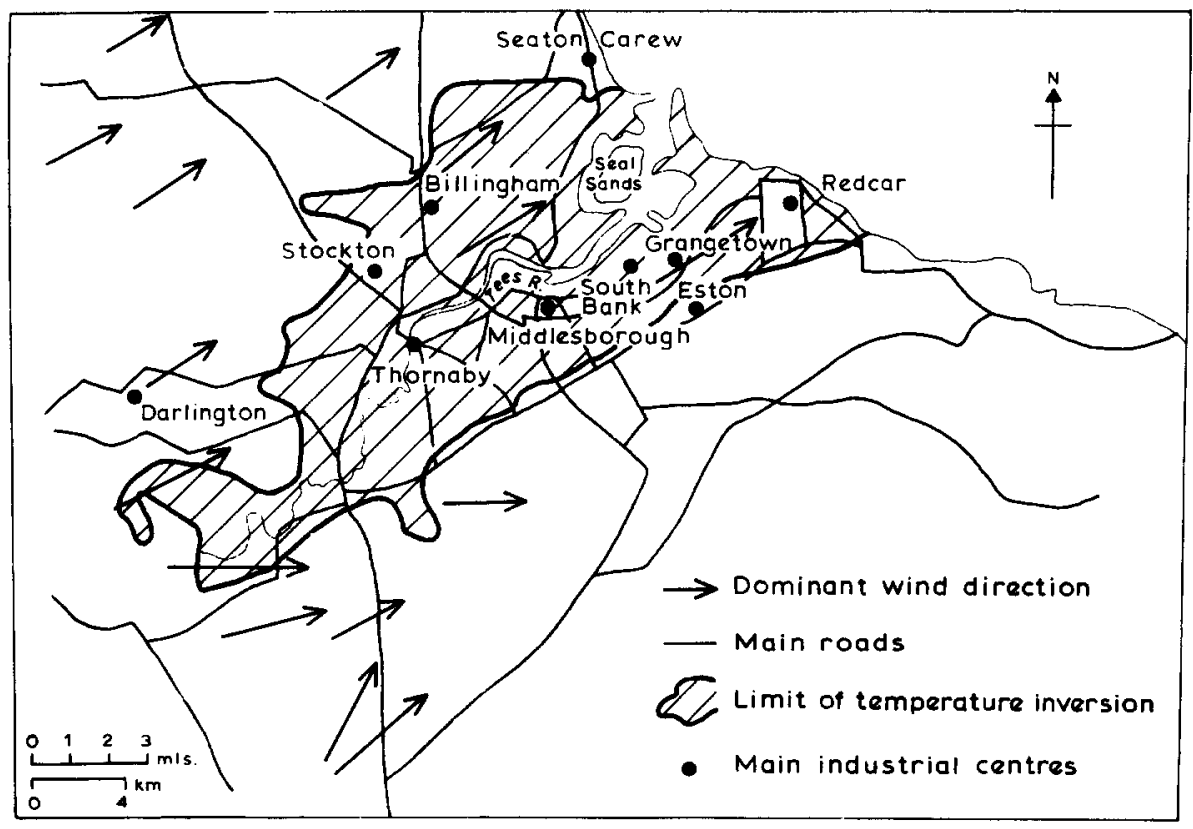

Fig. 1. Study area, Teesside. 
west of Thornaby on the south bank of the River Tees, and from Seaton Carew to Stockton on the north bank. The scale of the multiband photography is $1: 5000$. It was taken in late summer/early autumn 1971. Photographic coverage also exists at other scales (e.g. 1:28,000, 1:20,000), and at various times of the year. The Teesside area's main industrial activities include two large chemical works, four British Steel Corporation iron and steel works, an oil refinery and power stations, as well as many other types of industry.

\section{THE POLLUTION PROBLEM}

Levels of atmospheric pollution on Teesside, although high, are not higher than other comparable industrial areas. However, the climate and topography of Teesside combine, at certain times of the year, to make for periods with much higher levels of atmospheric pollution.

\section{Climate}

The prevailing wind direction on Teesside lies between south and west (Fig. 1); southerly winds blow for $18.7 \%$ of the year, southwesterly for $27.6 \%$ and westerly for $12.7 \%$. Winds from the north and north-east form the second most important general direction. They blow for about $20 \%$ of the year, mainly during spring and summer. These winds are more gentle than those from the south-west, as they are often the result of anticyclonic conditions. These conditions frequently lead to the formation of temperature inversions, during which cooler air is trapped close to the ground, making for a high incidence of fog at these times of the year. The effects of the fog are greatly intensified by atmospheric pollution.

\section{Topography}

The Teesside area is situated in a huge basin coming from the Vale of York and opening up into the North Sea. Another important factor is the extremely low elevation of the basin and estuarine floor. The River Tees flows approximately northeastwards, and the major industries are situated at, or near, its banks along this axis. Hence, for the greater part of the year, the smoke and other polluting gases are blown northeastwards by the southwest winds, downriver and out to sea, affecting only those urban and vegetated areas close to the river and downwind of the sources of pollution, but adversely affecting the coastal vegetation and environmental quality of the seaside resort of Redcar (Fig. 1).

During the critical weeks in spring, it is the gentle north east winds which blow into urban Teesside. Mists generated at sea and over the damp, low-lying estuarine sands slowly move upriver, holding the gaseous pollutants within them. This moist cool air hangs heavily in the Tees Valley, giving characteristic inversion conditions below the $100 \mathrm{ft}(30 \mathrm{~m})$ contour, weakening the sunlight, darkening the 
day, and thereby reducing the photosynthesis of plants during their critical growth period. This climatic condition would occur every year, with or without the urban/ industrial area, and without the air pollutants. Thus it is clear that the degree of atmospheric pollution in the Teesside area is temporarily enormously exaggerated at a critical time of year-from an ecological point of view-by unavoidable dense fogs and mists. The limit of the temperature inversions, with their attendant problems of fog and impounded air pollution, is at the $30 \mathrm{~m}$ contour. Above this $30 \mathrm{~m}$ inversion level, and on either side of the pollution cone, pollution levels drop sharply and substantially. This drop is borne out quite clearly by the multiband photographic survey carried out on the health and growth of the plants above and below the $30 \mathrm{~m}$ contour in the Teesside area, reflecting that plants, as recorded on aerial photography, are highly sensitive to atmospheric pollution.

A major function of the Tees river is the disposal of effluent. The degree of pollution varies greatly along its length, being extremely bad downstream of the Stressholme sewage plant. Below the Stockton and Billingham areas down to the sea, the tidal Tees is regarded as one of the most polluted rivers in England (Teesside Survey and Plan, 1969 ; p. 320). The tidal polluted zone forms an almost deadly barrier to migratory fish (e.g. salmon and trout). The port function of the river is vital to the industrial economy of Teesside, and extensive dredging is required to maintain a navigable channel $20 \mathrm{~km}$ upriver to Stockton.

\section{THE VEGETATION PROBLEM}

Before discussing the methods of examining vegetation stress by means of multiband remote sensing photography, the effects of pollution on plants should be considered as a basis for the subsequent arguments.

It has long been recognised that smoke in the air of towns and around industrial sites has an adverse effect on photosynthesis, by reducing the light intensity and hours of bright sunshine per day. Quality as well as quantity of light is affected, since the absorption and scattering of radiation is greatest in the ultra-violet range. This, as will be shown later, makes the use of infrared film (which cuts off these shorter wavelengths-see Fig. 2) extremely desirable in areas with high levels of atmospheric pollution. As the concentrations of smoke are highest in winter, due to the domestic demand, the greatest reduction of light occurs at this season, when both light intensity and hours of daylight are at their lowest. The majority of agricultural and horticultural crops will be little, if at all, affected by this reduction of winter light, since they will be either dormant or not in the ground at this time, but some effects might be expected on crops such as spring cabbage, glasshouse plants, grass, etc.

The light energy available for photosynthesis is also reduced by the blackening of leaves by grit and dust. In the main, grit and dust particles are heavy, and settle 


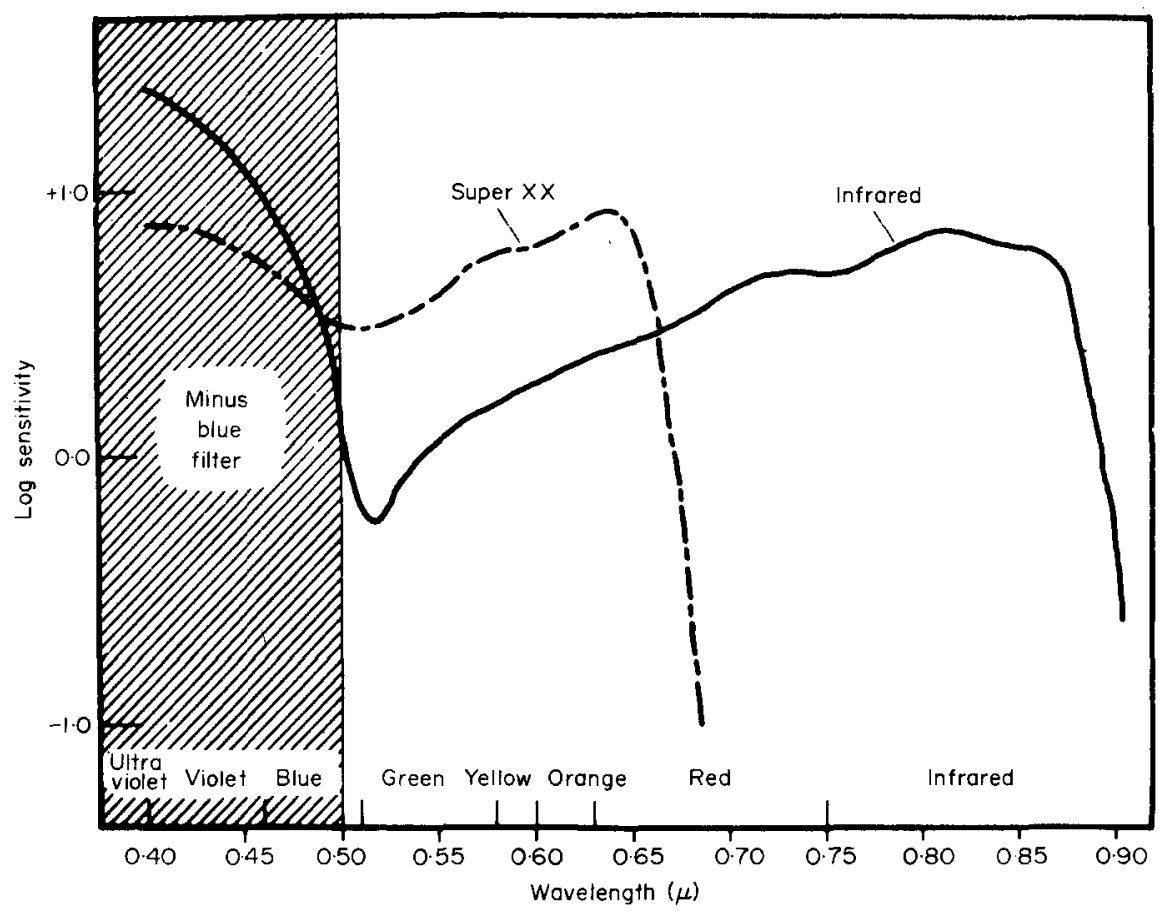

Fig. 2. Spectral sensitivity of Kodak Infrared Aerographic film and Kodak Super XX Aerographic film, at various wavelengths. Note the effect of the minus blue filter and the cut-off wavelengths for both films. (After National Academy of Science, 1970, page 40.)

out of the atmosphere quite quickly. The problems and effects on the vegetation, as observed on the aerial photographs, thus tend to be fairly local in nature, being most acute close to the source, then decreasing rapidly. The main effect is an environmental one, where the ubiquitous deposit of dust simply depresses the scene. The absence, or sickly growth, of vegetation only emphasises the condition.

In the Teesside area there have been numerous reports of severe damage to vegetation caused by heavy sulphur dioxide pollution in and around the major industrial plants of the area. The degree of dispersal and dilution of the $\mathrm{SO}_{2}$ depends on various factors such as climatic conditions and the height of the emitting chimney. Clear evidence exists of its deleterious effects on vegetation. Depending on its concentration, the season, and other climatic factors, the harmful effects of sulphur dioxide range from retardation of growth to death by poisoning. The most striking examples of damage have been observed on the downwind side of the large chemical plants at Billingham and Wilton, and in the neighbourhood of the four large iron and steel plants. While steps have been, and are still being, taken to reduce the pollution and the resulting damage, examples of severe and extensive 
damage to vegetation can still te found. Various considerations need to be taken into account when examining vegetation stress due to $\mathrm{SO}_{2}$, by means of multiband aerial photography, as the effects of atmospheric sulphur dioxide pollution of plants depend on the concentration of the gas and the length of time that the plants are exposed to it, as well as the variable pattern of exposure if this is intermittent, or if gas concentrations fluctuate. Susceptibility also varies with species, stage of growth and time of day, as well as being affected by environmental factors such as air temperature and humidity, light intensity, water supply, etc.

\section{MULTIBAND REMOTE SENSING RESULTS}

Before pollution effects on vegetation can be determined on aerial photographs, it is necessary that a stress situation should exist in the vegetation. Vegetational stress situations imaged in the visible and near infrared parts of the electro-magnetic spectrum can be used diagnostically from the geomorphological, soil and geological points of view to examine effects of drought, flooding, soil moisture and geomorphological features on vegetation (e.g. Svensson, 1972). This paper is confined to the development of a programme for the detection of vegetation stress resulting from pollution from the physiological point of view.

Much detailed work has been done on detecting diseased trees and crops, but these applications are of limited use in a study of vegetation stress due to pollutional effects, since they are limited to locating infected trees after the foliage has visually faded. (The term 'faded' is a colloquial expression for a dying tree showing visible discoloration of foliage on aerial colour photography.) Many studies have shown that vegetation under stress responds differently from healthy vegetation in various portions of the electro-magnetic spectrum. The type of vegetation stress being investigated by airborne multiband remote sensing is atmospheric and water pollution damage to both natural vegetation and cultivated crops.

Of the three types of photographs taken by the multiband camera (viz. blackand-white panchromatic, colour, and colour-infrared), the colour-infrared (falsecolour) film has been found the most useful remote sensing device for vegetation stress analysis. There are several properties specific to false-colour film which makes it particularly suited to sensing pollution effects on vegetation.

Panchromatic black-and-white and normal colour film sense only wavelengths in the visible portion of the electro-magnetic spectrum, while colour-infrared film is sensitive to both visible and near infrared portions of the spectrum (Fig. 2). Since film dyes used in colour-infrared are made sensitive to different portions of the spectrum, false colours appear on colour-infrared film, where green appears blue, red appears green, and near infrared wavelengths appear red (Fig. 3). Since most forms of vegetation have high reflectance in the near infrared region, they take on an orange-red/red-to-purple hue. This method of vegetation enhancement has been 
found to help greatly in detecting vegetation and the quality of vegetation in industrial and urban areas. This, in turn, has aided in the determination of environmental quality.

Colour-infrared film has been found to be important in vegetation-stress studies, since, with it, healthy trees can be separated from trees under stress. The stress effect may be either with or without visible crown symptoms in nature, and this fact points to the great usefulness of this type of film. With the colour film, only the difference between healthy trees and those under stress, with visible crown symptoms, is shown. Another important advantage of Kodak Ektachrome Infrared
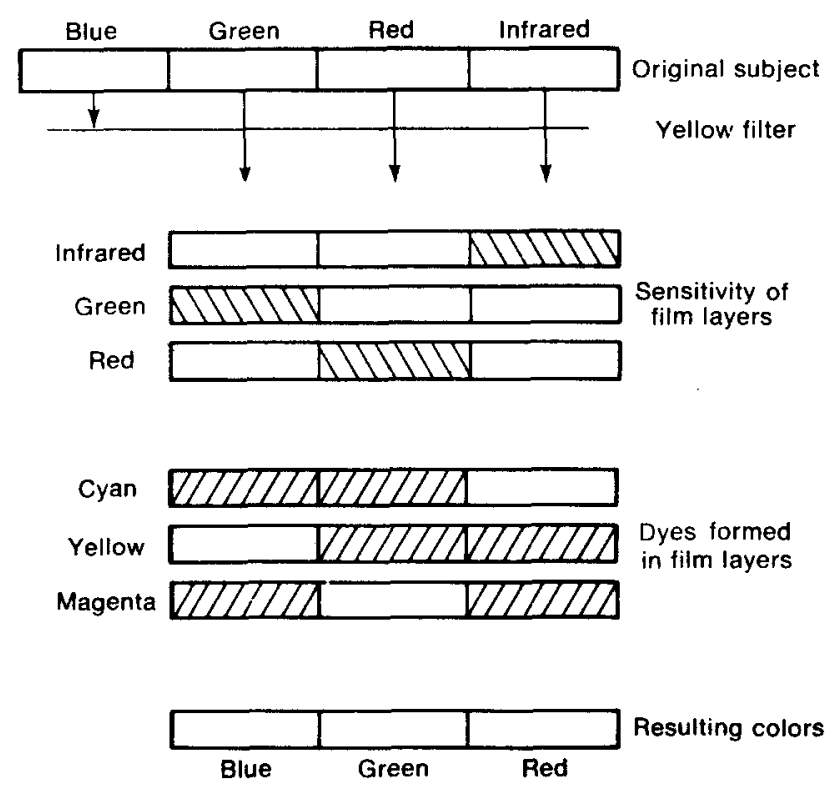

Fig. 3. Colour formation with infrared colour film.

Aero film over full colour film is that, on the former, conifers and broad-leaved species were easily differentiated, while this is not the case for colour film. As conifers are usually far more sensitive to atmospheric pollution, this is an important extra advantage of false-colour film.

In addition, atmospheric scattering of visible and near infrared wavelengths due to the reflection of dust particles, smoke, water vapour, $\mathrm{SO}_{2}$, etc., does not affect colour-infrared film to the same degree that it affects other photographic sensors, thus giving colour-infrared a strong haze and smog penetration ability, so valuable in studying industrial areas. This is so because, as has been mentioned earlier, atmospheric scattering takes place mainly in the short blue-light wavelengths which are filtered out of the colour-infrared image (Figs. 3 and 4). Other reasons 
why false-colour film has better smoke and haze penetration than black-and-white panchromatic and colour film are the facts that the infrared reflectivity and absorption characteristics of vegetation usually enhance the subject contrast, and the ratio of vegetation brightness to atmospheric brightness is usually increased by higher reflectivity of scene details to infrared radiation.

Infrared and visible radiation are often reflected and transmitted quite differently by vegetation. For example, chlorophyll in live, green foliage and grass absorbs a large percentage of the visible radiation which falls upon it, but transmits most of the infrared. This radiation is reflected by the leaf and blade mesophyllic structure.

Because of the special properties of infrared colour film, healthy foliage records red, whereas verdure under stress photographs in other distinctive colours (Fig. 4). Figure 4 shows the results of this investigation, and, at the same time, why the vegetation colours show up as they do. This key should not be considered as the final product, but simply as the first stage in a programme to detect areas of vegetation under stress. It can easily be modified, and extended. A key such as this allows one to understand how and why the various vegetation types are recorded as they are.

The following discussion on the characteristics of vegetation stress-as recorded by false-colour film-should, therefore, be considered by constant reference back to Fig. 4. Healthy broad-leaved species, which reflect mainly in the infrared range, and, to a smaller extent, in the green range, show up as red on the false-colour film. Conifers, which have less infrared and more green reflectance, result in an image which contains less red and more blues. In general, the reddish photographic rendition of healthy trees was observed to grade into magenta, purple and green as the loss of infrared reflectance progressed. Damaged conifers often stood out as bright yellow spots. Leaves and needles which were diseased or partly damagedsymptoms which were either visible or invisible on black-and-white. panchromatic and colour film, depending on the degree of damage-registered as light-grey or pink on the film, depending on the stage of the damage. A light-grey impression was obtained when the reflection caused response in all photographic layers, so that no dye was formed (Fig. 4). Leaves and needles which were dead, having no reflectance in the infrared range, formed a cyan image. On the false-colour film, dead conifers were often visible by their green colour, and trees which appeared grey also indicated the presence of a stress condition.

Some effects of oil pollution that were observed on the multiband photographs were the yellowing and death of oiled leaves, while chronic pollution may completely eliminate vegetation. Some of the factors influencing the effects of oil pollution on vegetation were noted to be the type and amount of oil involved, the degree of its weathering, the species and age of the plants concerned.

Infrared colour film was also very efficient in detecting sources and extent of polluted water. Many water pollution problems have arisen because the sources are unknown, the consequences not observed soon enough, and the effects not appreci- 


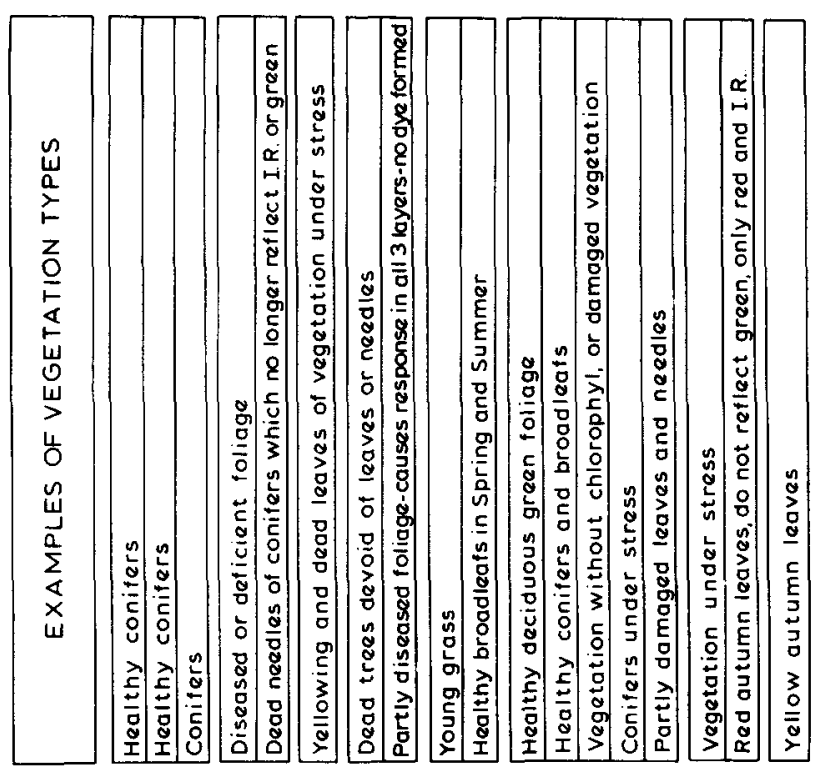

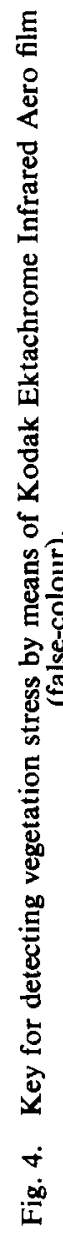

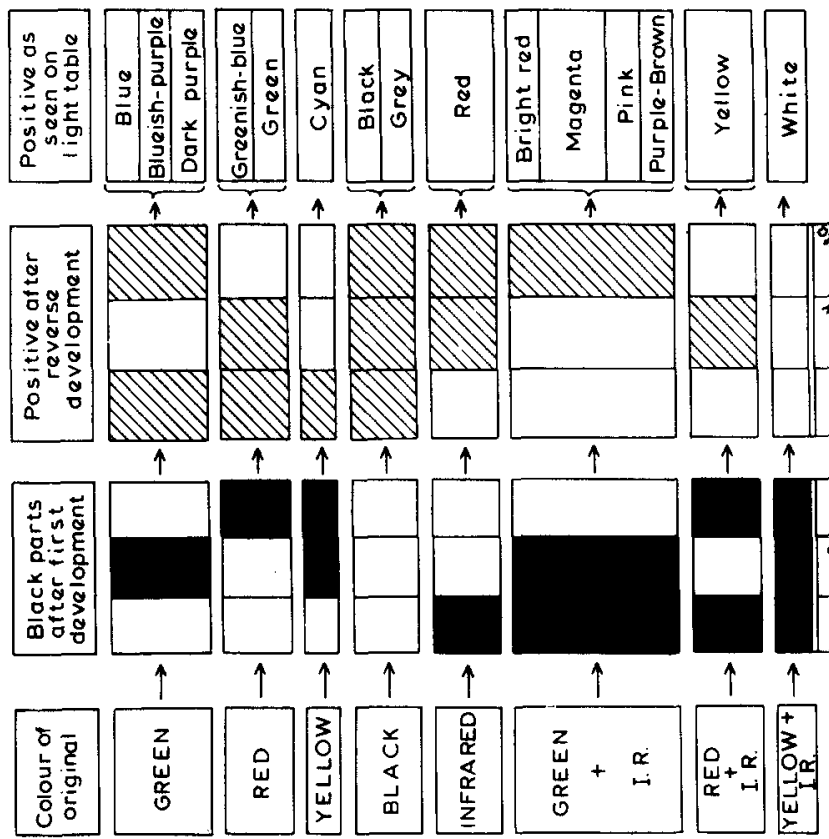


ated by those authorities delegated to control such matters. Aerial infrared photography has been found able to detect critical source areas, thereby reducing the time taken on necessary field work. On the infrared colour film, clear water photographed black, water suffused with algae, red, water with a low dissolved oxygen level, milky, and vegetation growing near the outfalls of chemical exotics in a cyan hue. These changes could not be seen on the colour or black-and-white panchromatic photographs.

Coupled to the advantages listed above is the fact that colour-infrared transparencies were found to be easier and more rapid to interpret than panchromatic black-and-white and normal colour photographs.

\section{SUGGESTED PROGRAMME OF WORK}

As a result of the preliminary investigation, it is considered that the following tasks need to be examined in order for a study of the effects of pollution on vegetation to be effective.

1. It is necessary, first of all, to plot all the sources of pollution, particularly atmospheric and water pollution. Multiband photography is a relatively simple and very fast method of plotting all the chimneys by means of stereoscopy. A map indicating types of industry is also readily made from aerial photographs. From this, the type of pollution emitted can be determined. Multiband photographs are also very effective for locating areas expelling untreated sewage into the river, as well as for pinpointing all industrial discharges flowing directly or indirectly into the river. Again, the map of industrial sites prepared from the aerial photographs will give a possible indication of the nature of the chemicals being discharged.

In the field, the Local Authority's Health Inspector's Department has $\mathbf{4 2}$ deposit gauges, 35 standard $\mathrm{SO}_{2}$ instruments and 3 Philips $\mathrm{SO}_{2}$ monitors. The location of these, when plotted on the multiband images, can be related to the type of industrial plants in their vicinity.

2. The next task is to map the vegetation of the area, so that this can then be correlated with the sources of pollution. Again, this can be done from the multiband aerial photographs, especially from the colour-infrared photographs. Such a vegetation/land-use map, together with the map of type of industry/sources of pollution, forms the basis of the investigation.

3. The next and most important phase of this kind of study concerns the actual determination of areas of vegetation under stress as a result of pollution. The preceding section on Multiband Remote Sensing Results has indicated methods of achieving this, being summarised in Fig. 4. Wind direction is considered to be very important, so that the dominant wind directions should be plotted and the vegetation on the upwind and downwind sides of the source of pollution can then be compared. Hildebrandt \& Kenneweg (1968) have done some excellent work in this 
field. They plotted the vegetation downwind of a major chimney, dividing the trees into four categories-healthy, trees under slight stress, trees under considerable stress, and dead trees. Their results were plotted on a grid basis, so that their experiment can be repeated at regular intervals. To make this perhaps even more meaningful, the types of emission could also be grouped into four categories after the maps of vegetation stress have been made. These could be: (i) insignificant (i.e. no effect on the development function, physiological well-being, power of propagation, etc.); (ii) considerable; (iii) severe and (iv) excessive. Again, a grid basis can be used, so that the increase or decrease in atmospheric effects on vegetation can be repeated as and when required.

4. Sequential photography will also prove to be invaluable in this type of study where vegetation stress conditions need to be examined over long periods of time. Thus sequential aerial photography can be used to plot the changes in the number and size of industrial plants, and changes in type, number and height of chimneys, changes in the number and intensity of sewage and industrial disposal points, etc., as well as being able to determine the increase, if any, in the stress put on vegetation as a result of the ever-increasing amount of environmental pollution.

5. Field checks of the vegetation should preferably be made in the same season as the imagery is taken, as the possibility exists that the stress suffered by the trees is only temporary or seasonal. Thus tree crowns may recover after air pollution decreases. This is especially so in areas with highly fluctuating levels of $\mathrm{SO}_{2}$ concentration.

6. Since pollution from a particular point is diluted by wind turbulence as it is blown along, it is obvious that low level sources, emitting within the very turbulent layers nearest the ground, produce maximum ground level concentration very near the source. In average winds it is reckoned that high emitters (e.g. tall industrial chimneys) produce maximum ground level concentrations at a distance downwind of the chimney of 10-15 times the height of the chimney (Warren Spring Laboratory, 1972). The height of all emitters can be measured quite accurately from the aerial photographs by means of a simple parallax bar.

7. Multiband aerial photography is only one of several remote sensing techniques available to study effects of pollution on vegetation. Other proven methods have been by means of thermal infrared and multispectral scanners (Olson, 1971; Weber \& Polcyn, 1972; Wert, 1969).

8. Image enhancement techniques such as density slicing and microdensitometry appear particularly useful in plotting the spread of water pollution in the estuary, and for distinguishing subtle tonal differences of the vegetation.

\section{RECOMMENDATIONS AND CONCLUSIONS}

In order to determine areas of vegetation under stress as a result of pollution, it is necessary first of all to locate the sources of pollution, and then compare the 
vegetation in the zones of high pollution with those in relatively unpolluted areas. Such a comparison is no simple task, for an area of either natural vegetation or a crop may yield different photographs in different years, even if the photographs are taken in the same season each year. In addition, aerial photographs taken with an interval of only a few days during the same year may show up differently, with different features in the vegetation either fading out or assuming greater prominence. Thus it is obviously important to consider the external conditions (i.e. physical and meteorological) that prevailed and influenced the vegetation both before and at the time of photography.

The loss of near infrared reflectance of vegetation under stress can be caused by a number of damaging agents besides atmospheric and water pollution, including pathogens, insects, frost injury, mineral deficiency, drought and flooding. Thus much of the land made available for afforestation is marginal, and many factors that adversely affect the trees and other vegetation may be encountered, such as low temperatures, exposure to high winds, shallow or poor soil, poor drainage, etc. Consequently, it seems that many reports of poor growth or death of trees due to pollution require close investigation.

Hence it is important to realise that multiband aerial photographs do not inform the interpreter about the agent causing the vegetation damage or mortality.

However, the problem of determining the agent responsible for a loss in vegetation vigour is usually not as hopeless as the foregoing two paragraphs might imply. In many cases, a given vegetation type, growing in a particular locality, experiences almost all its loss in vigour as a result of a single damaging agent. Once the cause of damage has been established by careful on-the-ground checks (e.g. of vegetation close to, and downwind of, major industrial plants), further mapping of vigour losses by means of photographic tone differences seen in that vegetation is tantamount to mapping the location where that agent (i.e. atmospheric pollution) reaches a level sufficient to cause damage.

The problem of the control of grit and dust is being improved in the Teesside area, not only by better methods of arrestment, but also by the closure of older industrial plants in areas such as Ironmasters. The setting up of green belts around the major plants will not only act as effective filters of the dust and grit, but will, at the same time, improve the environmental scenery by hiding the industrial eyesores. However, such trees must endure heavy stress, so that it is important to choose pollution-resistant species for this tree-planting. By means of studying the multiband photographs, it is possible to deduce which trees thrive best under such conditions. Less than $4 \%$ of the area is woodland. Tree-planting, whether in the form of forest, woodland or hedgerow, is one of the cheapest and speediest ways in which to transform the 19th century image of industrial Teesside.

The pollution from gaseous sources is a matter of much more concern, as this is tending to increase, and, unlike grit and dust, gases disperse widely. The main existing sources are on the banks of the Tees downstream of Stockton, where 
climatic and topographic factors intensify their effects. With the overwhelming advantages of Seal Sands for future industrial development, further pollution problems will be created. The careful monitoring of the effects and changes produced by such development by means of multiband aerial photography will allow rapid remedial action to be applied.

This study has shown the need for extensive ground instrumentation, to establish stress parameters in trees, and also to provide vital ground truth for airborne multiband data. One needs to be able to answer questions about changes in plant physiology and biophysical responses of stressed vegetation in relation to seasonal and diurnal changes in the environment.

In conclusion, the investigation has supported the premise that the value of multiband aerial photography in all studies of foliage and verdure under stress lies in the early and relatively easy detection of the stress condition. Multiband remote sensing can also locate the sources and extent of environmental pollution, as well as indicate remedial steps, making their application quick and efficient.

\section{REFERENCES}

AgRicultural Research COUNCIL (1967). The effects of air pollution on plants and soil. London, HMSO.

BRANDT, C. S. (1962). Effects of air pollution on plants. In Air pollution, ed. by A. C. Stern, 251-81. New York, Academic Press.

HeCK, W. A. (1966). The use of plants as indicators of air pollution. Int. J. Air Wat. Pollut., 10, 99-111.

HildebrandT, G. \& KeNNEWEG, H. (1968). Beispiele forstlicher Interpretations-möglichkeiten falschfarbiger Luftbilder. Congress of the International Society for Photogrammetry, 11th, Commission VII, Lausanne.

Olson, C. (1971). Remote sensing of the broadleaf trees under stress. Proc. int. Symp. PhotoInterpretation, 3rd, Dresden, 689-96.

POLLANSCHÜTZ, J. (1968). Erste Ergebnisse über die Verwendung eines Infrarot-Farbfilmes in Österreich für die Zwecke der Rauchschadensfeststellung. Zentbl. ges. Forstw., 85, 65-79.

SVENSSON, H. (1972). The use of stress situations in vegetation for detecting ground conditions on aerial photographs. Photogrammetria, 28, 75-88.

Teesside Survey and Plan (1969). London, HMSO. 3 vols.

THOMAS, M. D. (1961). Effects of air pollution on plants. In Air pollution. Geneva, World Health Organization.

WARREN SPRING LABORATORY (1972). National survey of air pollution, 1961-1971. London, HMSO.

WeBer, F. P. \& PolcYN, F. C. (1972). Remote sensing to detect stress in forests. Photogramm. Engng, 38, 163-75.

WERT, S. L. (1969). A system for using remote sensing techniques to detect and evaluate air pollution effects on forest stands. Proc. int. Symp. Remote Sensing of Environment, 6th, 2, 1169-78. Ann Arbor.

WolfF, G. (1967). Kronenschaden an Fichte im St. F.B. Marienberg und ihre Diagnose im Falschfarben-Luftbild. Die Socialistische Forstwirtschaft, 5, 148-51.

\section{ADDITIONAL REFERENCES}

ANON. (1969). Air pollution. Proceedings of the first European Congress on the Influence of Air Pollution on Plants and Animals, Wageningen, 1968. Wageningen Centre for Agricultural Publishing and Documentation. 
ANON. (1968). A national programme of research for environmental quality-pollution in relation to agriculture and forestry. Washington, D.C., Joint Task Force of the US Department of Agriculture and the State University and Land Grant Colleges.

BERGE, H. (1970). Differentiation and evaluation of air pollution from a botanical point of view. Environ. Pollut., 1, 141-8.

BIEBERDORF, F. W. et al. (1958). Vegetation as a measure indicator of air pollution. Bull. Torrey bot. Club, 85, 197-200.

Brady, N. C. (ed.) (1967). Agriculture and the quality of our environment. Publ. Am. Ass. Advmt Sci., No. 85.

Colwell, R. N. (1967). Remote sensing as a means of determining ecological conditions. BioScience, 17, 444-9 and cover.

England, H. M. \& Berry, W. T. (eds.) (1971). Proceedings of the Second International Clean Air Congress. New York and London, Academic Press.

Freeman, O. F. \& BennetT, I. L. (1969). A report to the President-Control of agriculture-related pollution. Washington, D.C.

Gordon, A. G. \& GoRhAM, E. (1963). Ecological aspects of air pollution from an iron sintering plant at Wawa, Ontario. Can. J. Bot., 41, 1063-78.

Grimes, B. H. (1972). Preliminary report of the River Tees. London, Nature Conservancy.

HAAGEN-SMr, A. J. et al. (1952). Investigations on injury into plants from air pollution in the Los Angeles area. Pl. Physiol., 27, 18-34.

Halitsky, J. (1961). Single-camera measurement of smoke plumes. Int. J. Air Wat. Pollut., 4, $185-98$.

Hepting, G. A. (1964). Damage to forests from air pollution. J. For., 62, 630-4.

House, J. W. \& Fullerton, B. (1960). Teesside at mid-century. London, Macmillan.

House, J. W. (1969). Industrial Britain: the North East. Newton Abbot, David and Charles.

Johnson, P. L. (ed.) (1969). Remote sensing in ecology. Athens, Georgia, University of Georgia Press.

Joint Conference on Sensing of Environmental Pollutants (AIR). Palo Alto, California, 8-10 November 1971.

KATZ, M. (1949). Sulphur dioxide in the atmosphere and its relation to plant life Ind. Engng Chem. ind. Edn, 41, No. 11.

LUDWIG, G. B. et al. (1968). Study of air pollutant detecting by remote sensors. General Dynamics Report GDC-DBE 68-011 under NASA contract NAS-12-630.

Metcalfe, C. R. (1953). Effects of atmospheric pollution on vegetation. Nature, Lond., 172, 659-61.

Middleton, J. T. et al. (1958). Damage to vegetation from polluted atmosphere. J. Air Pollut. Control Ass., 8, 9-15.

National Research Council (1970). Remote sensing, with special reference to agriculture and forestry. Washington, D.C., National Academy of Sciences.

Rohde, W. G. \& Olson, C. E. (1970). Detecting tree moisture stress. Photogramm. Engng, 36, 561-6.

SCHNEIDER, S. (1972). Environmental control from airborne and space vehicles. Paper presented at Commission VII, 12th Congress of the International Society for Photogrammetry, Ottawa.

STELLINGWERF, D. A. (1969). Kodak Ektachrome infrared aero film for forestry purposes. ITC Publication, Series B, No. 54.

Surts, G. \& LEGAult, R. (1973). An overview of remote sensing of air pollution. Paper presented at the Symposium on Remote Sensing of Environmental Pollution, Milan, 28 January 1973.

Treshow, M. (1965). Evaluation of vegetation injury as an air pollution criterion. J. Air Pollut. Control Ass., 15, 266-9.

Veress, S. A. (1970). Air pollution research. Photogramm. Engng, 36, 840-8. 